\title{
Research Paper \\ Structural relationships of metacognitive and motivational beliefs with students' procrastination based on the mediating role of learning strategies
}

\author{
Hossein Pourmousa Bzanjani ${ }^{1}$, Mohammad Ali Mohammadifar ${ }^{2}$, Seavash Talehpasand ${ }^{2}$, Ali Mohammad Rezaei ${ }^{2}$ \\ 1. Ph.D Student in Educational Psychology, Semnan University, Semnan, Iran. \\ 2. Associate Professor, Department of Psychology, Semnan University, Semnan, Iran.
}

Citation: Pourmousa Bzanjani H, Mohammadifar M.A, Talehpasand S, Rezaei A.M. Structural relationships of metacognitive and motivational beliefs with students' procrastination based on the mediating role of learning strategies. J of Psychological Science. 2022; 20(108): 2211-2224.

URL: https://psychologicalscience.ir/article-1-1449-fa.html
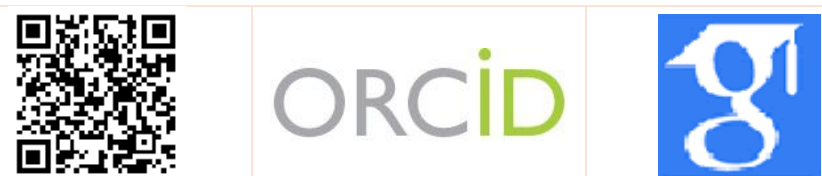

10.52547/JPS.20.108.2211

\section{A R T I C L I N F O A B S R A C T}

Keywords:

Metacognitive beliefs, motivational beliefs, learning strategies, academic procrastination

Received: 18 Oct 2021 Accepted: 11 Nov 2021 Available: 10 Feb 2022
Background: Following the cognitive-behavioral theory, cognitive constructs such as underlying beliefs have been shown to affect components of information processing, encryption, and other cognitive processes. Thus, academic procrastination is a behavior that can follow cognitive beliefs and constructs such as metacognitive beliefs and motivational beliefs, and can also be influenced by cognitive processes such as learning strategies.

Aims: This study aimed to identify the factors affecting procrastination and its causal mechanisms. This study investigated the structural relationships between students' metacognitive and motivational beliefs and their procrastination with a focus on the mediating role of learning strategies.

Methods: The correlation method was used to model structural equations. The research population included undergraduate students $(n=27670)$ of Kerman universities. A total of 400 students were selected using multi-stage random cluster sampling as the respondents based on their responses to the items in the Metacognitive Beliefs about Procrastination Questionnaire (MCPQ; Fernie et al., 2009), Self-Regulation Learning Strategies Scale (Pentrich \& De Grout, 1990), Learning and Study Strategies Inventory (LASSI; Weinstein \& Palmer, 2002, and Academic Procrastination Scale (APS, McCloskey, 2012). The collected data were analyzed through structural equation modeling.

Results: Metacognitive beliefs both directly $(\beta=0.57, p=0.0001)$ and indirectly $(\beta=0.17, p=$ 0.009 ) have a positive and significant effect on academic procrastination through learning strategies. Also, it was found that motivational beliefs have an indirect and significant effect on academic procrastination only indirectly $(\beta=-0.41, \mathrm{p}=0.01)$ through learning strategies.

Conclusion: Following the cognitive-behavioral theory, it can be argued that metacognitive beliefs and motivational beliefs as underlying beliefs can affect information processing as cognitive processes and lead to various behavioral consequences. Academic procrastination occurs following cognitive beliefs and constructs and can also be influenced by cognitive processes.

* Corresponding Author: Mohammad Ali Mohammadifar, Associate Professor, Department of Psychology, Semnan University, Semnan, Iran.

E-mail: alimohammadifar@ semnan.ac.ir

Tel: (+98) 2333623300

2476-5740/ (C) 2021 The Authors. This is an open access article under the CC BY-NC-ND license (https://creativecommons.org/licenses/by-nc/4.0/). 


\section{Extended Abstract}

\section{Introduction}

One of the problems affecting learners and people engaged in various educational and professional fields is procrastination (Razeghi, Mir Hosseini, \& Zargham Hajebi, 1399). Procrastination occurs when people carry out their activities with a delay. Thus, the present study seeks to find out how academic procrastination is created and what factors account for it. Following theoretical-cognitive-behavioral theories and previous studies in the literature, metacognitive beliefs (Ziegler \& Opdenacker, 2016; Cikersi, 2016) and motivational beliefs (Hannock, 2011; Serino, 2014) can be identified as the underlying causes of academic procrastination.

Metacognitive knowledge (metacognitive beliefs) refers to the information that individuals hold about their own cognition and about strategies which influence it (Wells, 2002).

Motivational beliefs also refer to the three components of expectation (learners' beliefs about doing a task), value (learners' beliefs about the interest and importance of the task) and emotions (emotional reactions to the task) (Pantrich \& DeGrote, 1990). Learning strategies also include three levels of skill, will, and self-regulation helping students achieve their goals so that they have a good understanding of the curriculum and can use a variety of strategies, including thinking and information processing; relating new information to previous knowledge, and integrating the lesson material into their minds (Weinstein, McDermott, \& Rudiger, 2010).

According to Beck (1979), any behavior experienced by a person is based on his or her beliefs. A person's cognition screens, encrypts, organizes, stores, and retrieves information. Academic procrastination is also a behavior that can occur following cognitive beliefs and structures and can also be influenced by cognitive processes. Moreover, according to the cognitive-behavioral theory and a review of the literature, information processing and cognitive processes such as learning strategies can mediate the relationship between metacognitive beliefs and motivational beliefs with academic procrastination.
To investigate this hypothetical model, the structural equation modeling method was used in this study.

\section{Method}

The statistical population of this study included all undergraduate male and female students of Kerman universities (27670 people) who were studying in the first semester of the academic year 2020-201. To determine the sample size, the number of routes tested in the model was selected as the criterion. A minimum of 10 and a maximum of 20 people can be selected for each route. In the present study, 20 people were selected for each route using multi-stage cluster random sampling. First, the questionnaires were designed in Google Forms to be completed online by the respondents due to the COVID-19 outbreak. After making arrangements with the professors, the link of the questionnaire was provided to students of Kerman universities through online social groups. That there were 20 paths in the research model. The number of participants was estimated at 400 students. The data were collected using the Metacognitive Beliefs about Procrastination Questionnaire (MCPQ; Fernie et al., 2009), Self-Regulation Learning Strategies Scale (Pentrich \& De Grout, 1990), Learning and Study Strategies Inventory (LASSI; Weinstein \& Palmer, 2002, and Academic Procrastination Scale (APS, McCloskey, 2012).

In the present study, confirmatory factor analysis was run to evaluate the validity of the instruments, and Cronbach's alpha method was used to evaluate their reliability. The results of confirmatory factor analysis showed that all items had significant correlations with their subscales. Moreover, fit indices were reported for each optimal scale. The Cronbach's alpha coefficients were also reported to be within acceptable ranges for the scales and subscales.

\section{Results}

Based on the theoretical framework of the study and a review of the literature, a model was designed in which metacognitive beliefs and motivational beliefs were considered as exogenous variables, academic procrastination as endogenous variables, and learning strategies as mediating variables.

To investigate the significance of the mediating role of learning strategies in the relationship between 
metacognitive beliefs and motivational beliefs with academic procrastination, the bootstrap command was used in AMOS software.

As can be seen in Table 1 , metacognitive beliefs $(p=0.009, \beta=0.17)$ positively affect academic procrastination through learning strategies. It was shown that motivational beliefs $(p=0.01, \beta=-0.41)$ negatively affect academic procrastination through learning strategies.

Table 1. Indirect and total impact coefficients in the model using bootstrap

\begin{tabular}{cccc}
\hline Direction & Indirect effect & $\mathrm{P}$ & Total effect \\
\hline Metacognitive beliefs - Learning strategies - Academic procrastination & $0 / 17$ & $0 / 009$ & $0 / 73$ \\
Motivational beliefs - Learning strategies - Academic workload & $-0 / 41$ & $0 / 01$ & $-0 / 42$ \\
\hline
\end{tabular}

\section{Conclusion}

In general, the results of this study showed that a person following metacognitive beliefs and motivational beliefs can use effective learning strategies. Such a person is less likely to experience academic procrastination. Because by applying these strategies, a person fosters positive academic outcomes and has a more efficient performance.

According to these findings, educational packages can be developed according to the cognitivebehavioral theory to foster metacognitive and motivational beliefs and teach learning strategies to students to help them face less academic procrastination. Moreover, other cognitive variables related to the cognitive process such as information processing, learning styles, decision making, problem solving, and other similar variables can mediate the relationship between fundamental beliefs and procrastination.

This study was carried out with some limitations. For instance, due to the COVID-19 outbreak, most of the students had to attend online courses. This restricted the researcher's access to the students, making data collection a bit more difficult. In addition, since the respondents in the present study were students of Kerman universities, one should be careful in generalizing the findings to other societies.

\section{Ethical Considerations}

Compliance with ethical guidelines: This article is an excerpt from a doctoral dissertation. The students participated in the study consciously and voluntarily and could leave the response process whenever they wished. In addition, no risk was perceived for the participants.

Funding: Not applicable.

Authors' contribution: 50\% of this research project was completed by first author and $50 \%$ by the supervisors and advisors.

Conflict of interest: There was no conflict of interest in this study.

Acknowledgments: The authors wish to appreciate the cooperation of the students and the officials at the Faculty of Psychology and Educational Sciences and the Department of Educational Psychology of Semnan University. 


\section{روابط ساختارى باورهاى فراشناختى و انتيزشى با اهمال كارى دانشجويان براساس نقش واسطهاى راهبردهاى يادكيرى}

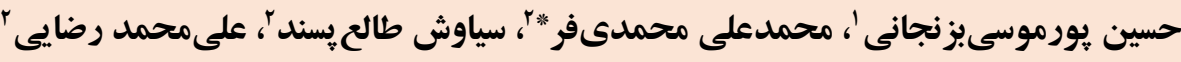

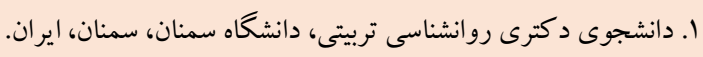

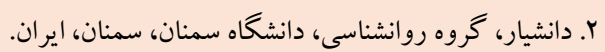

جكيده

زمينه: براساس نظريه شناختى - رفتارى؛ مشخص شده است كه ساختارهاى شناختى مانند باورهاى زيربنايى بر مؤلفهاى برداز شأش اطلاعات،

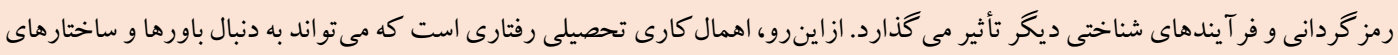

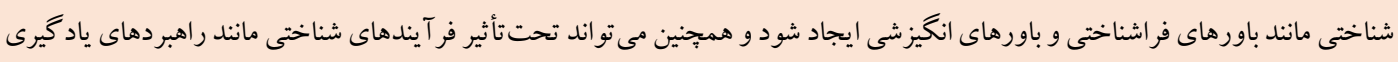
قرار گيرد.

هدف: به بررسى روابط ساختارى باورهاى فراشناختى و انخيزشى با اهمال كارى دانشجويان براساس نقش واسطهاى راهبردهاى يادگيرى ير يرداخته شد. روش: براى رسيدن به اين هدف از روش همبستخى در قالب مدل يابى معادلات ساختارى استفاده شد. از بين جامعها آمارى دانشجويان دوره

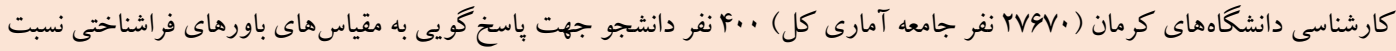

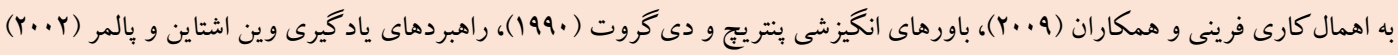

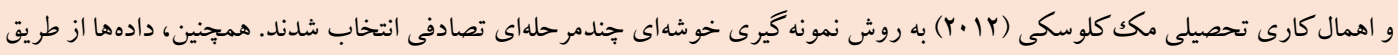

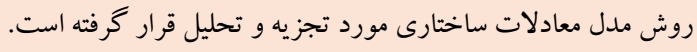

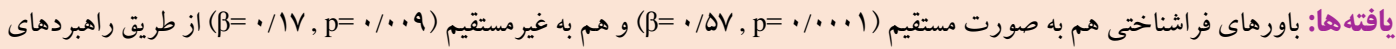

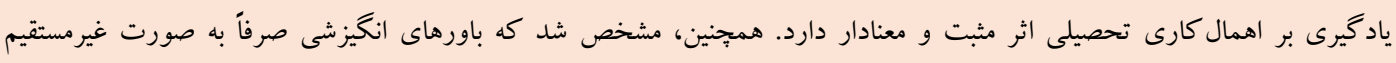

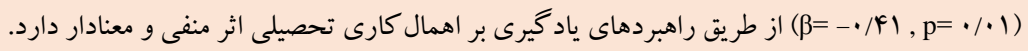

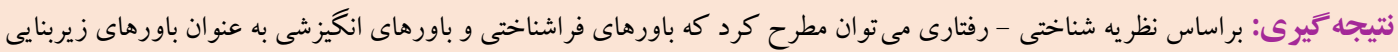

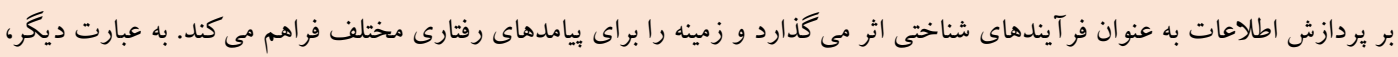

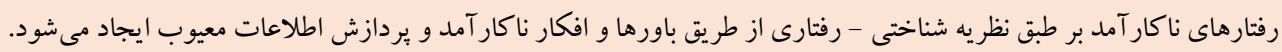

مشخصات مقاله

كليدوازهها:

باورهاى فراشناختى،

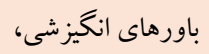

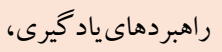

اهمال كارى تحصيلى

دريافت شده: If

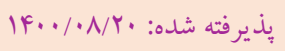

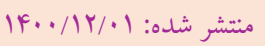

* نويسنده مسئول: محمدعلى محمدىفر، دانشيار، دانشيار، گروه روانشناسى، دانشكاه سمنان، سمنان، ايران. رايانامه: alimomammadifar@semnan.ac.ir 
او به وجود مى آيد، اين بخش ساختار شناختى يا همان طرحواره است كه

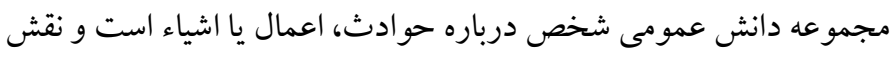

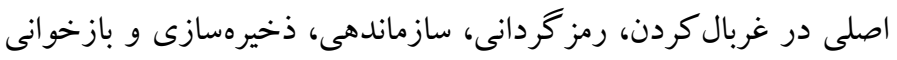

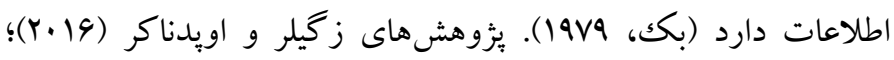

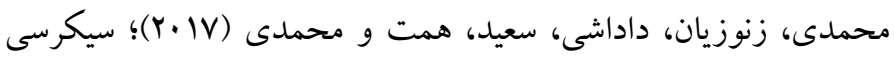
(Y.19) و مداحى (1949) به صورت ضمنى مشخص كردند كه باورهاى فراشناختى مى توانند اهمال كارى تحصيلى را بيشينى كنيند. همجنين،

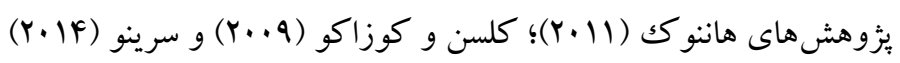

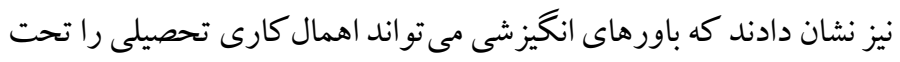

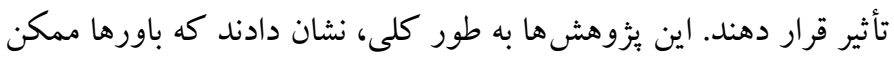

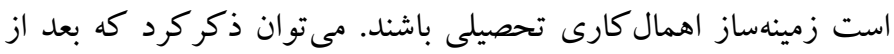

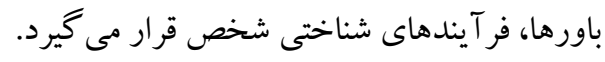
فراشناخت مفهومى جند جنبهاى است. دانش فراشناختى يا همان باورهاى فراشناختى، اطلاعاتى است كه افراد در مورد شناخت خود و راهبردهاى تراى

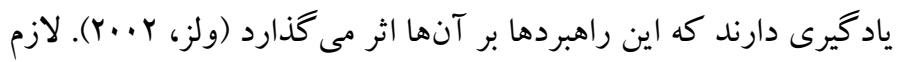
به ذكر است كه باورهاى فراشناختى در حوزهى آسيبشناسى نيز با ظهور

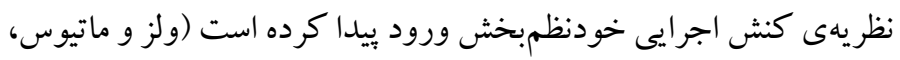
1999). بر طبق اين نظريه اختلالات روانشناختى وقتى تداوم مى يابند كه وردئ

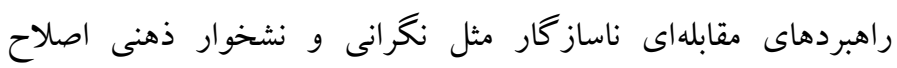

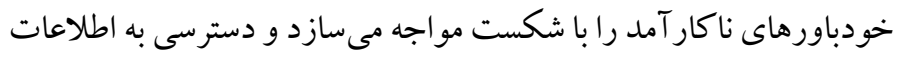

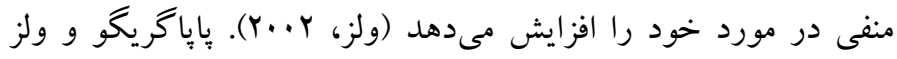
(Y...r) جهت ارزيابى روانسنجى افكار و باورهاى فراشناختى به مؤلفه هاى باورهاى مثبت و باورهاى منفى اشاره نمودند. اين باورها همان

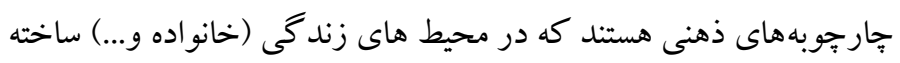

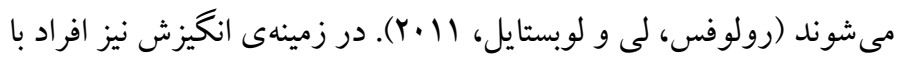
باورهاى مختلف روبهرو هستند، منظور از اين باورهاى انگيزشى، معيارهاى شخصى و اجتماعى است كه افراد براى يك عمل بدان مراجعه مى كنند و

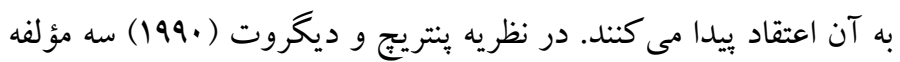

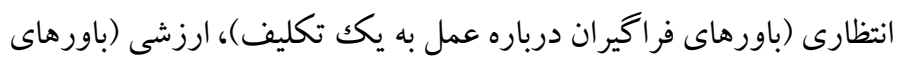

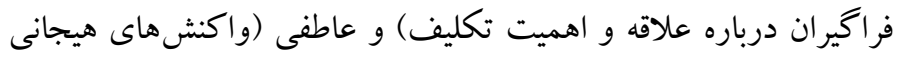
نسبت به تكليف) مد نظر قرار گرفته است. راهبردهاى يادگيرى به عنوان بعد يردازش شناختى در نظريه شناختى - رفتارى مى تواند مطرح شوند. dolo

يكى از مسائل و مشكلاتى كه ياد گيرندگان و افراد فعال در زمينههاى

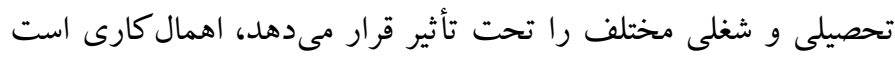

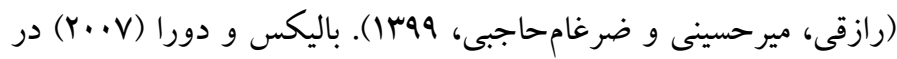

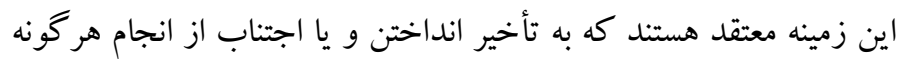
تكليف كه ناشى از اختلاف رفتار بين قصد و رفتار واقعى است و براى فرد نتايج منفى به همراه داشته باشند، اهمال كارى تلقى مى شود. به تاخير

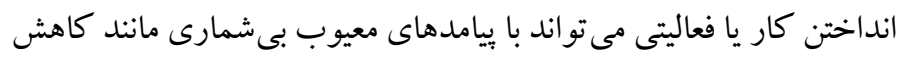

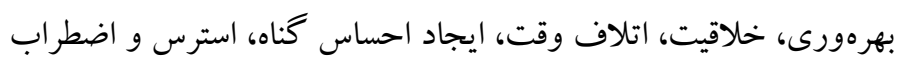
شديد و عدم تأييد اجتماعى همراه باشد. شيوع بالاى اين آسيب يكى از

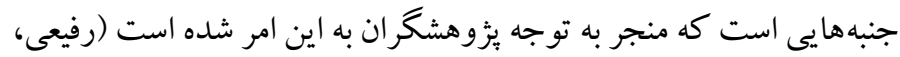

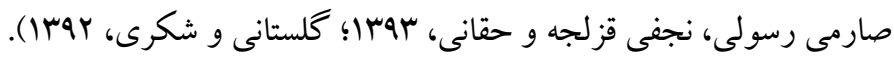
مطالعات نشان مىدهد كه عللى از جمله علل شخصيتى (ملتفت و رنجبر، Faf

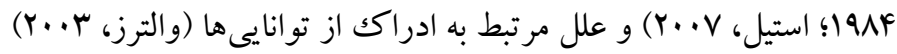
در اهمالكارى نقش بسزايى دارند. در حوزهى علل شخصيتى به تفاوتهاى فردى از جمله ترس از شكست، كمال گرايى (شاهرخى و ورى

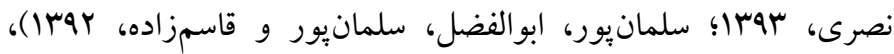

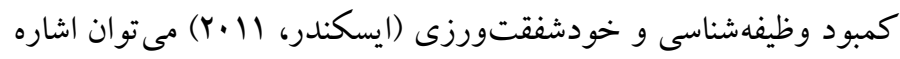
كرد. در زمينهى علل وابسته به تكليف مىتوان به بيزارى از تكليف، اضطراب وابسته به تكليف، ارزش تكليف، فشار زمانى و مديريت زمان

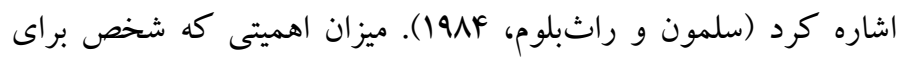
تكليف قائل است، داشتن زمان زياد براى انجام تكليف و نداشتن تخمين

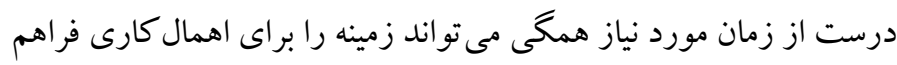

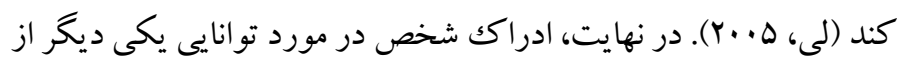
علل مربوط به اهمال كارى است. داشتن عزتنفس، خود كار آمدى و و

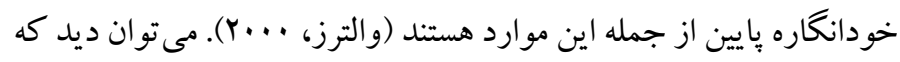
شناخت در هر سه علل نقش محورى دارد. بر بايهى نظريه و درمان شناختى - رفتارى، انسان در بافت هاى مختلف مانند خانواده، محيط مدرسه و... باورهايى را به دست مى آورد كه ديد او را نسبت به آينده مىسازد. اين باورها مى تو انند زمينهساز مؤلفههاى شناختى - رفتارى ماند اهمال كارى در تحصيل باشند همانطور كه بك معتقد است رفتار شخص در بيى باورهاى 
اشاره كردهاند كه اهمالكارى تحصيلى مىتواند در بي راهبردهاى

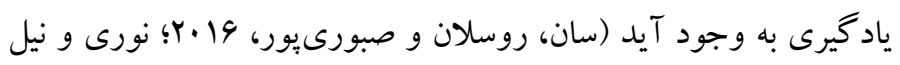

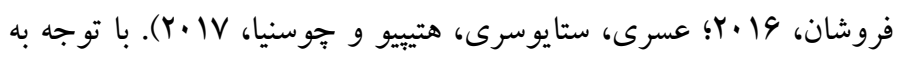
مطالب مطرح شده مى توان اين فرض را در نظر گرفت كه اهمال كارى

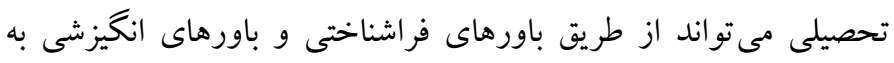

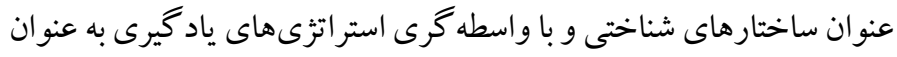
بخش بردازش اطلاعات نظريه شناختى - رفتارى بكك تحت تأثير قرار

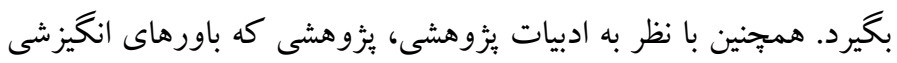

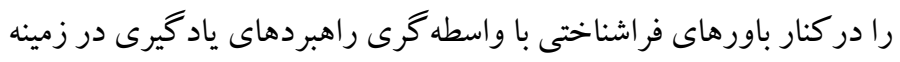
اهمال كارى تحصيلى مورد توجه قرار داده باشد، يافت نشد؛ لازم است به

$$
\text { بررسى اين مدل برداخته شود. }
$$

راهبردهاى ياد گيرى شامل سه سطح مهارت، اراده و خودتنظيمى مىشوند،

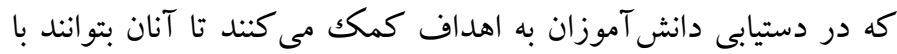

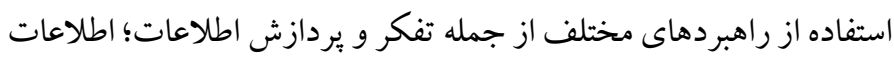

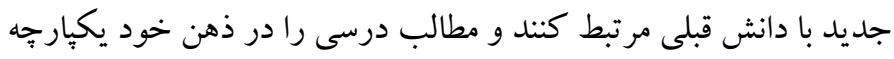

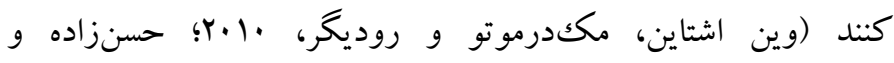

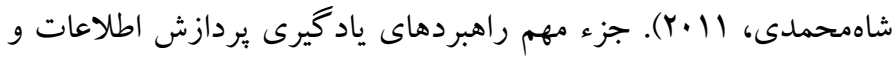
نحوهى تفكر است؛ مى توان آن را به عنوان بعد يردازش شناختى نظريه

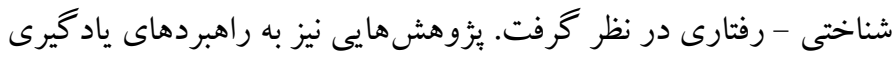

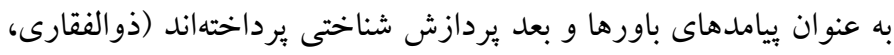

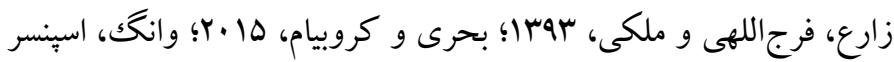

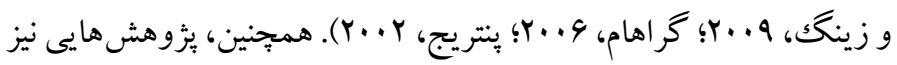

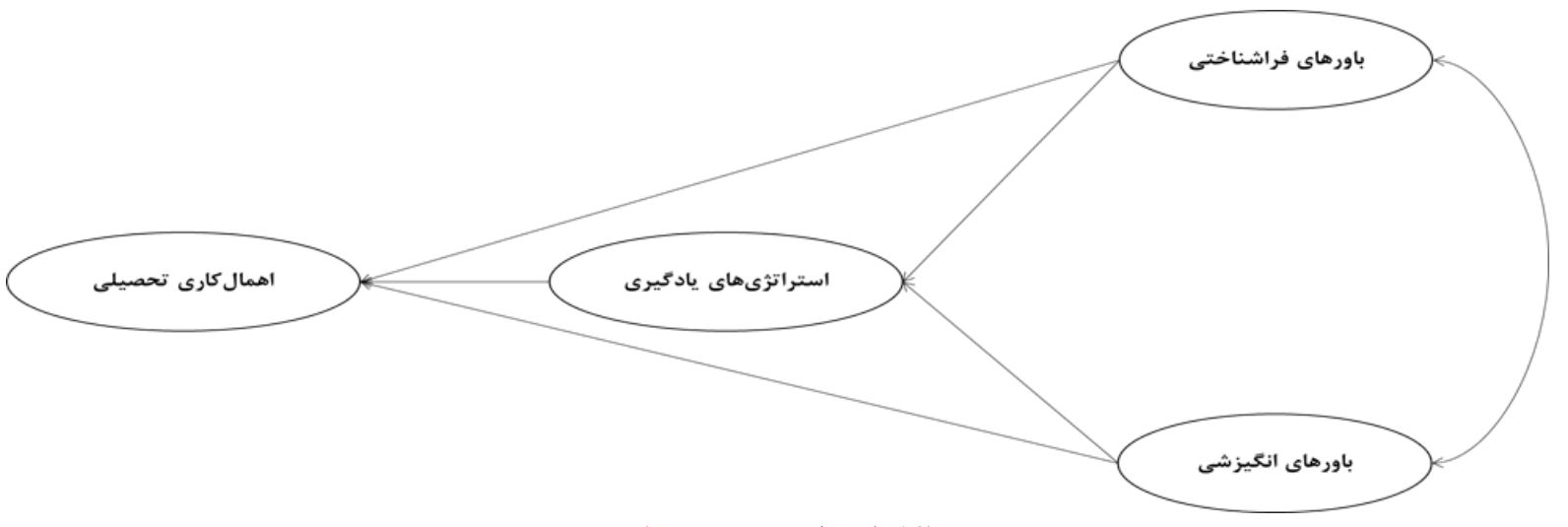

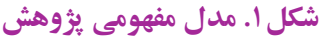

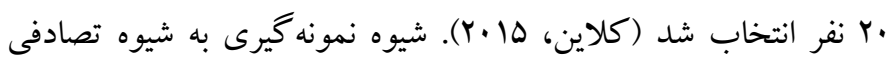

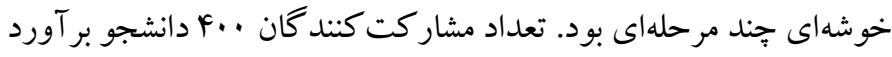

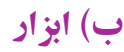

باورهاى فراشناختى مرتبط با اهمال كارى تحصيلى؛ اين مقياس توسط

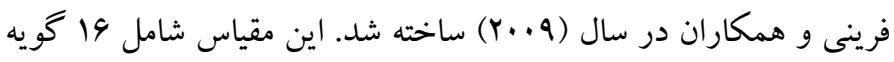
در دو خرده مقياس باورهاى مثبت نسبت به اهمال كارى و باورهاى منفى

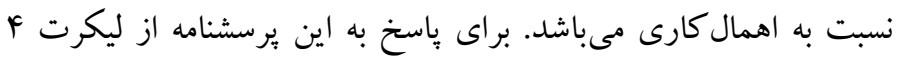
درجهاى استفاده شد. براى بررسى روايى اين مقياس از روش تحليل عامل

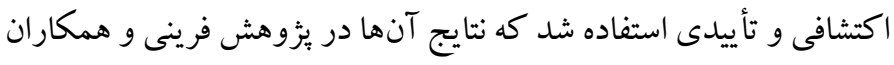

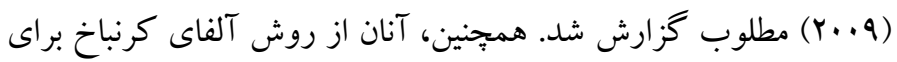

روش الف) طرح يثوهش و شر كت كنند كان: يُزوهش حاضر از نوع همبستحى در قالب مدل معادلات ساختارى است كه درآن روابط بين دو متغير

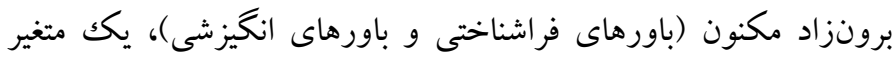

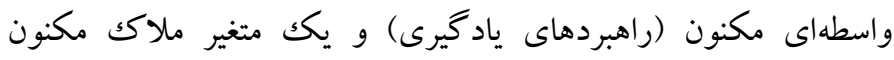
(اهمال كارى تحصيلى) مورد بررسى قرار گرفت. جامعهى آمارى اين

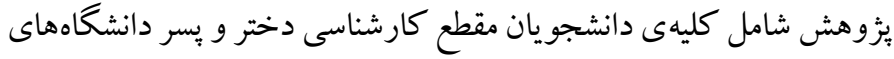

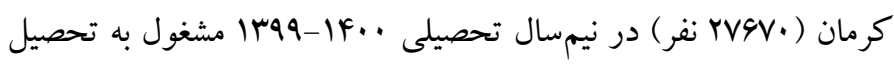
بوده است. به منظور تعيين حجم نمونه، تعداد مسيرهاى مورد آزمون در برد

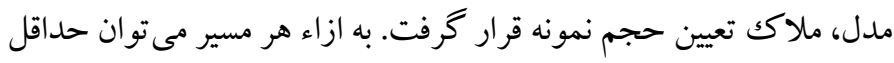
•ا و حداكثر ·r نفر را انتخاب كرد. در يزوهش حاضر به ازاى هر مسير 
راهبردهاى يادگيرى و مطالعه؛ براى بررسى راهبردهاى يادگيرى از سياهه

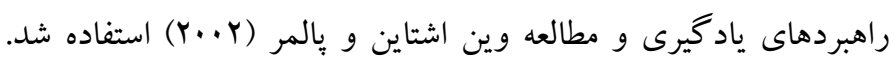

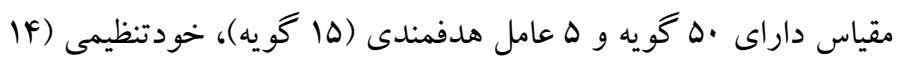

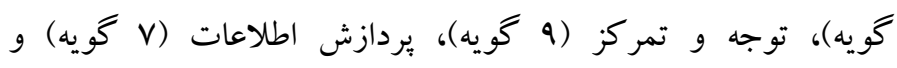
خودآزمايى (ه گويه) است. روايى و يايايى اين برسشنامه در آمريكا

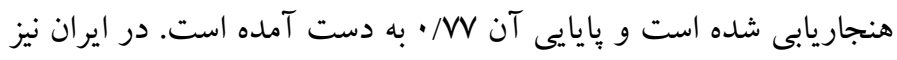
توسط زاهدى و فخرى (سوهו) روايى اين سياهه از طريق تحليل عامل

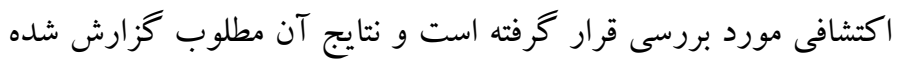

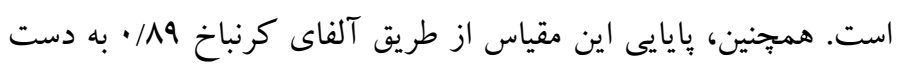
آمد (زاهدى و فخرى، سهوبا ).

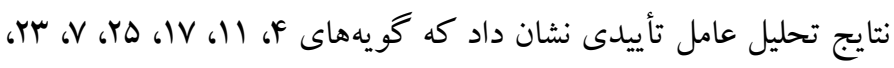

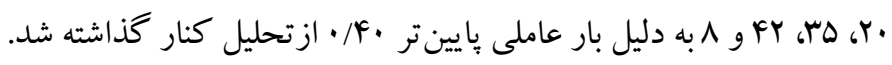

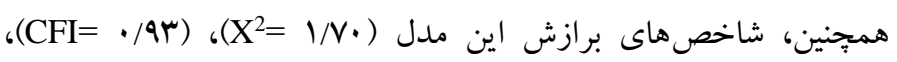
،(IFI= $\cdot / 9 r)$ ، (TLI= $\cdot / 94)$ ، (AGFI= $\cdot / \wedge 9) \quad$ (GFI= $\cdot / 91)$

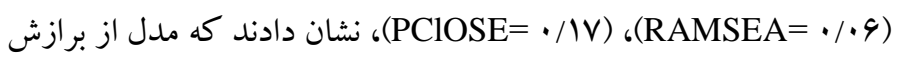
مطلوبى برخوردار است. همجنين، از روش ضريب آلفاى كرنباخ براى

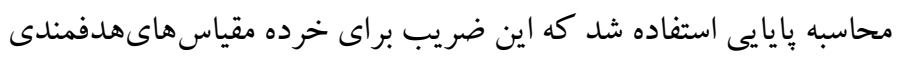
•/VV

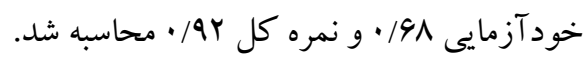
اهمال كارى تحصيلى؛ براى سنجش اهمال كارى تحصيلى از مقياس

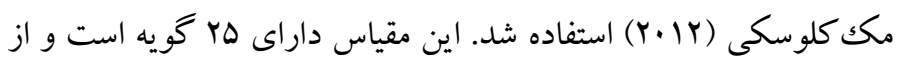
ليكرت ه درجهاى براى باسخ گويى به اين مقياس استفاده شده است.

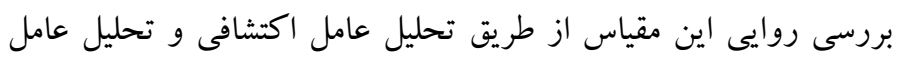

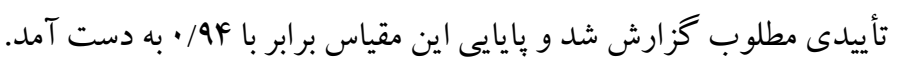

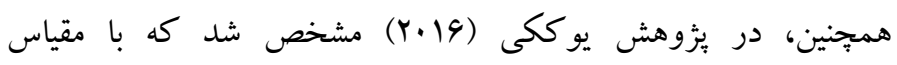

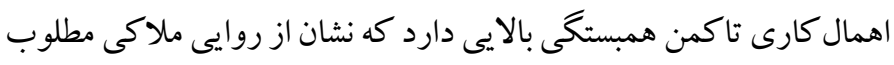

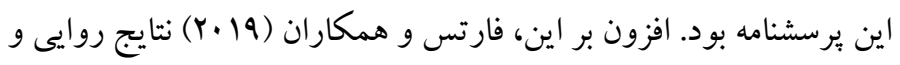

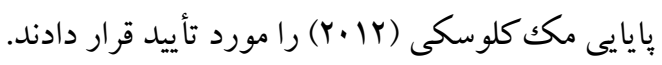
لازم به ذكر است كه اين مقياس براى اولين بار در اين بزوهش درد در ايران

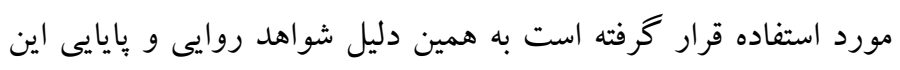

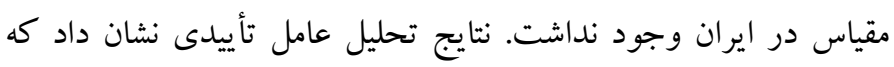

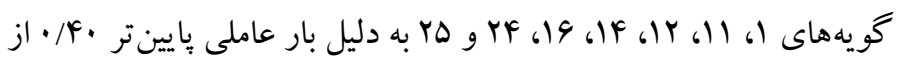

محاسبه پيايايى اين مقياس استفاده كردند كه نتايج آن براى خرده مقياس

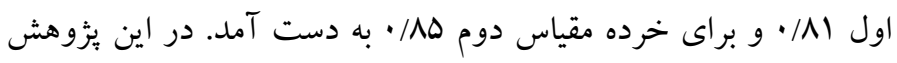

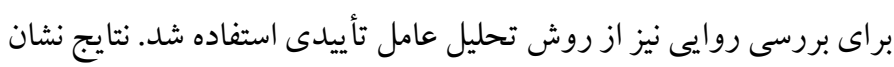

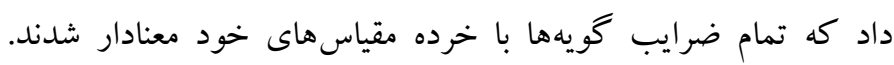

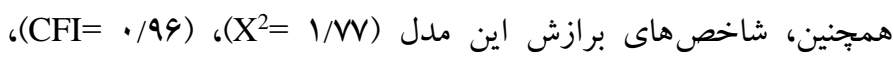

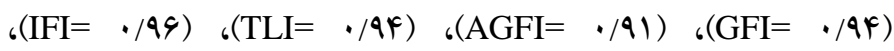

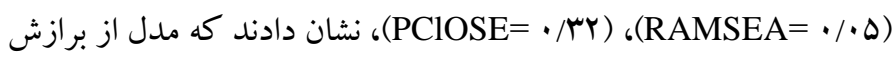
مطلوبى برخوردار است. همجنين، از روش ضريب آلفاى كرنباخ براى

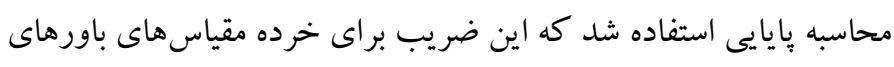

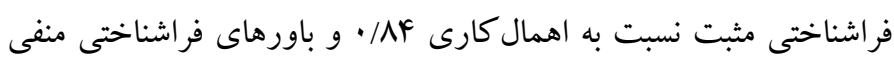
نسبت به اهمال كارى س^/ • محاسبه شد.

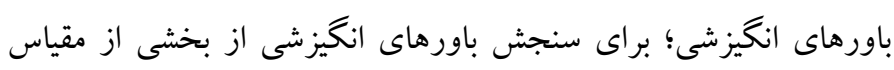

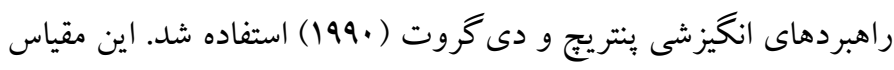

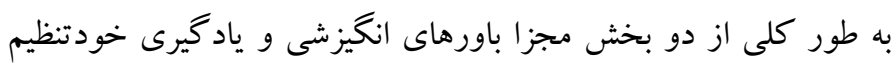

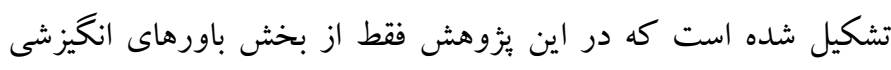

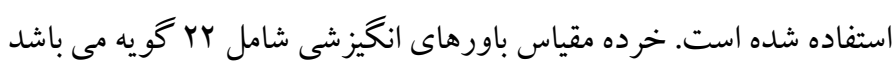

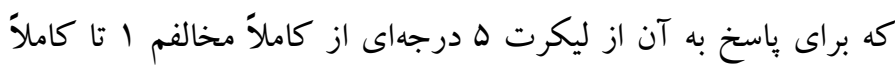

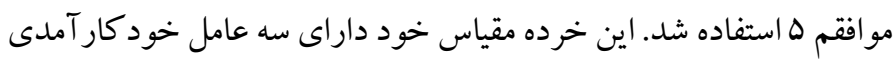

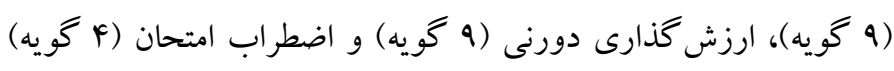

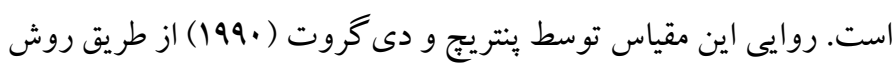

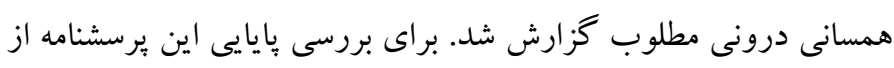

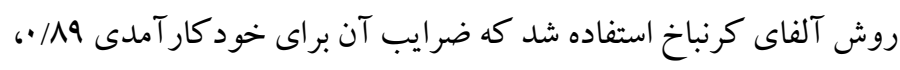

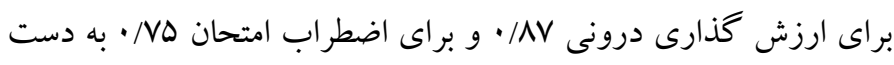

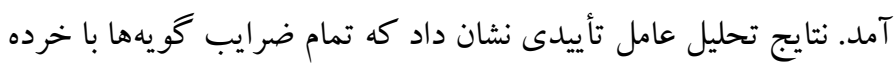

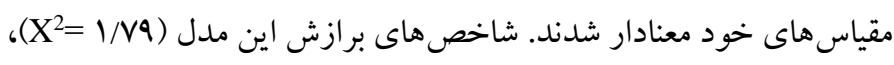

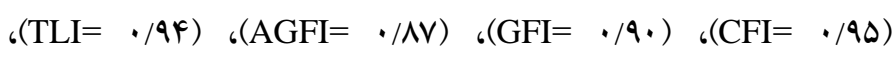

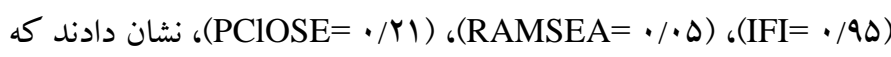
مدل از برازش مطلوبى برخوردار است. از روش ضريب آلفاى كرنباخ براى الها

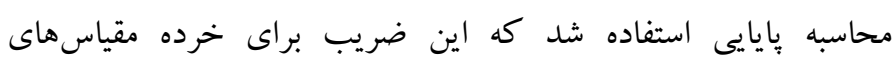

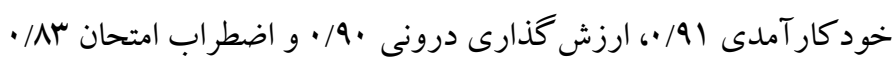
محاسبه شد. 
فرضيات يثزوهش يرداخته شده است. در ابتدا يافته هاى توصيفى مورد بررسى قرار گرفته است. در جدول ا ميانگين، انحر اف معيار، كمترين نمره و بيشترين نمره متغيرهاى يثوهش ارائه شده است. همانطور كه در جدول | بيشترين ميانگين مربوط به نمره كل راهبردهاى يادكيرى همجنين، بيشترين انحر اف معيار نيز مربوط به نمره كل راهبردهاى ياد گيرى با مقدار ها Yl/ به دست آمد. در جدول Y ماتريس همبستخى (مرتبه صفر) بين متغيرهاى بثزوهش نشان داده شده است.
تحليل كنار كذاشته شد. همجينين، شاخص هاى برازش اين مدل ${ }_{6}(\mathrm{AGFI}=\cdot / \mathrm{M}) \quad{ }_{6}(\mathrm{GFI}=\cdot / 9 r) \quad{ }_{6}(\mathrm{CFI}=\cdot / 94) \quad{ }_{6}\left(\mathrm{X}^{2}=\mid / 4 \mathrm{I}\right)$

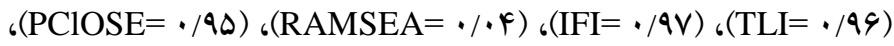
نشان دادند كه مدل از برازش مطلوبى برخوردار است. همجينين، از روش ضريب آلفاى كرنباخ براى محاسبه يايايى استفاده شد كه اين ضريب براى كل مقياس • (91 محاسبه شد.

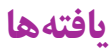
در اين بخش از ئزوهش به بررسى يافتهاى توصيفى و استنباطى براساس جدول ا. ميانتين، انحر اف معيار و حداقل و حداكثر نمرات متغير هاى ثئوهش

\begin{tabular}{|c|c|c|c|c|c|}
\hline بيشترين نمره & كمترين نمره & انحر اف معيار & ميانگين & 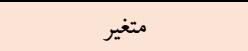 & نقش متغير \\
\hline rr & $\wedge$ & $\Delta / 11$ & $10 / 94$ & باورهاى فراشناختى مثبت & \multirow{5}{*}{ برونزاد } \\
\hline rr & $\wedge$ & $\Delta / \mu^{\prime}$ & $r \cdot / \Delta$. & باورهاى فراشناختى منفى & \\
\hline Fa & 9 & $\mathrm{~V} / \mathrm{l}$. & $\mathrm{rI/AI}$ & خود كار آمدى & \\
\hline Fa & 9 & $\mathrm{~V} / \cdot \mathrm{A}$ & $M / \Delta F$ & ارزش گذارى درونى & \\
\hline r. & r & $F / \cdot \Delta$ & $11 / 19$ & اضطراب & \\
\hline$\Delta \Delta$ & rr & $9 / \Delta \Delta$ & $\mathrm{rq} / \mathrm{Al}$ & هدفمندى & \multirow{6}{*}{ واسطهاى } \\
\hline 4. & 11 & $\mathrm{~V} / \cdot 1$ & $r q / r q$ & خو دتنظيمى & \\
\hline Fa & 9 & $V / .9$ & $r 9 / \Delta 1$ & تمركز و توجه & \\
\hline r. & r & $r / \cdot v$ & $\mid F / Y F$ & يردازش اطلاعات & \\
\hline r. & r & $r / 19$ & $I r / T V$ & خود آزمايى & \\
\hline r.. & $\mathrm{vA}$ & $r T / \Delta \Delta$ & $\mid r 9 / 19$ & نمره كل & \\
\hline 1.9 & $r$. & $1 F / \wedge q$ & GV/rT & اهمال كارى تحصيلى & د درونزاد \\
\hline
\end{tabular}

جدول r. ماتريس همبستغى مرتبه صفر متغير هاى ثزوهش

\begin{tabular}{|c|c|c|c|c|c|c|c|c|c|c|c|c|}
\hline Ir & 11 & 1. & 9 & $\wedge$ & V & 9 & $\Delta$ & F & $r$ & r & 1 & متغيّر ها \\
\hline & & & & & & & & & & & 1 & ا. باورهاى فراشناختى مثبت \\
\hline & & & & & & & & & & 1 & $\cdot / 19^{\text {独 }}$ & r. باورهاى فراشناختى منفى \\
\hline & & & & & & & & & 1 & $\cdot / 10^{* * * * *}$ & $-\cdot / \cdot r$ & r. خود كار آمدى \\
\hline & & & & & & & & 1 & $\cdot / Y^{* \text { *** }}$ & 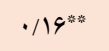 & $-\cdot / \cdot f$ & F. ارزش گذارى درونى \\
\hline & & & & & & & 1 & $-\cdot / \cdot F$ & $-\cdot / 1 \Delta^{\text {拳 }}$ & $\cdot / Y^{* * * * \pi}$ & $\cdot / r^{* * * * * *}$ & هـ اضطراب \\
\hline & & & & & & 1 & 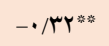 & $\cdot / \Delta 9^{\text {拳 }}$ & $.194^{* \% *}$ & $-\cdot / \cdot 1$ & $\cdot / Y V^{* 3 *}$ & 9. هدفمندى \\
\hline & & & & & 1 & $\cdot / N^{* * * * *}$ & $-\cdot / \Gamma \Delta^{* * *}$ & $\cdot / \Delta \cdot \cdot^{*}$ & $\cdot / \Delta \Lambda^{* * * *}$ & $-\cdot / \cdot v$ & $\cdot / Y F^{* * *}$ & V. خودتنظيمى \\
\hline & & & & 1 & 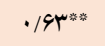 & $\cdot 19 Y^{\text {漛 }}$ & 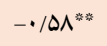 & 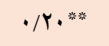 & • 每 & $-\cdot / Y 1^{\text {絭䖭 }}$ & 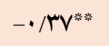 & ^ توجه و تمركز \\
\hline & & & 1 & $\cdot / 1 f^{* * *}$ & $\cdot / \Delta V^{* * *}$ & $\cdot / \Delta \Gamma^{* * * * *}$ & $-\cdot / \cdot f$ & $\cdot / \Delta \Delta^{\text {漛 }}$ & $\cdot / \& q * *$ & .1 .9 & $\cdot / \cdot r$ & 9. يردازش اطلاعات \\
\hline & & 1 & $\cdot 19 \Lambda^{\text {*** }}$ & $\cdot / 1 r^{* * * *}$ & $\cdot / \Delta F^{\text {拳 }}$ & $\cdot / \Delta r^{\text {券絭 }}$ & $-.1 \cdot 9$ & $\cdot / \Delta r^{\text {絭漛 }}$ & 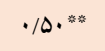 & $\cdot / \cdot \wedge$ & $\cdot / \cdot V$ & • ا. خود آزمايى \\
\hline & 1 & $\cdot 19 Y^{* * *}$ & $\cdot 19 \boldsymbol{r}^{* * *}$ & $\cdot / \sqrt{ } 9^{* * *}$ & $\cdot / 9 Y^{\text {*** }}$ & $\cdot / \wedge 9^{* * * *}$ & $-\cdot / F Y^{* * *}$ & $\cdot / \Delta V^{\text {券 }}$ & $\cdot / 9 \mu^{* * * *}$ & $-\cdot / \cdot V$ & $-\cdot / Y V^{*}$ & ا. نمره كل \\
\hline 1 & $-\cdot / F^{\text {拳 }}$ & $-\cdot / 4^{* * * *}$ & 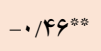 & $-\cdot|9|^{\text {*** }}$ & $-\cdot / V K^{* * * * 6}$ & 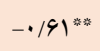 & 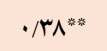 & 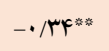 & 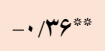 & $\cdot / \mid F^{*}$ & $\cdot / \mathrm{N}^{* * * *}$ & rا. اهمال كارى تحصيلى \\
\hline
\end{tabular}

* $\mathrm{P}<\cdot / \cdot 1$

$* \mathrm{P}<\cdot / \cdot \Delta$ 
همبستگى در دادههاى يزُوهش حاضر وجود نداشت. همجنين، براى بررسى دقيق تر هم خطى جند كانه از شاخصهاى اغماض و تورم واريانس (VIF)

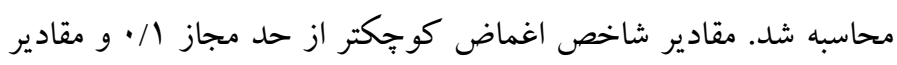

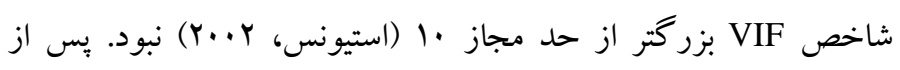
بررسى مفروضهها و حصول اطمينان از برقرارى آنها، به منظور ارزيابى مدل مورد بررسى از مدل معادلات ساختارى استفاده شد. نتايج در شكل ا ارائه شده است. براساس مبانى نظرى و بيشينه تحقيقاتى مدلى طراحى شد كه در آن باورهاى فراشناختى و باورهاى انكيزشى به عنوان متغير برونزاد، اهمال كارى تحصيلى به عنوان متغير درونزاد و راهبردهاى ياد گيرى به عنوان متغير ميانجى در نظر كرفته شد. برازش مدل نهايى بزوهش به تفكيك شاخص ها، در جدول ب گزارش شده است.
با توجه به نتايج مشاهده شده در اين جدول، روابط بسيارى از متغيرهاى برونزاد، واسطهاى و درونزاد به صورت مثبت و منفى معنىدار است.

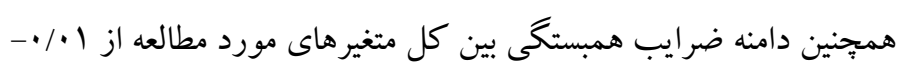
تا ra • • است. علاوه بر اين روابط بين متغير هاى يزٔوهش، در سطح 1 • • يا ه • • معنى دار شدهاند. همجينين، ييش از آزمون مدل معادلات ساختارى، به بررسى مفروضهها يرداخته شد. با استفاده از نرمافزار SPSS-24 و از طريق نمودار مستطيلى و آماره ماهالانوبيس دادههاى برت بررسى و از

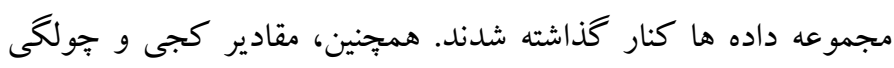
دادهها نيز بيشتر از ا土 نمىباشد. استقلال دادهها با آماره دوربين واتسون بررسى و تأييد شد. در بررسى هم خطى جند گانه از همبستكى بيرسون بين زوج متغيرها استفاده شد. با توجه به نظر تاياجنيك و فيدل (1 (. ب) كه همبستگى دو متغيرى •9/ • و بالاتر، همخطى ايجاد مى كند؛ اين مقدار

\begin{tabular}{|c|c|c|c|c|c|c|c|c|c|c|}
\hline PCLOSE & RMSEA & AGFI & TLI & RFI & IFI & NFI & CFI & $\mathrm{P}$ & $\mathrm{X}^{2} / \mathrm{df}$ & مدل \\
\hline$\cdot / \cdots 1$ & $\cdot / \cdot 1$ & .194 & $\cdot / A \mid$ & $\cdot / V^{\prime}$ & . Ar & $\cdot / \mathrm{VA}$ & $\cdot / A r$ &.$/ \cdots 1$ & $r / 90$ & قبل از اصلاح \\
\hline$\cdot / I V$ & $\cdot / \cdot \Delta$ & $\cdot / M$ & $\cdot / 9$. &.$/ 9$. &.$/ 94$ &.$/ 9 r$ &.$/ Q F$ & $\cdot / \cdots 1$ & $r / 19$ & بعد از اصلاح \\
\hline
\end{tabular}

از برازش مطلوبى برخوردار نبود. بس از انجام اصلاحات و حذف مسيرهاى بيشنهادى غير معنادار از مدل، برازش مدل مطلوب شد. يس از تعيين برازش مدل، وزن ركرسيون متغير هاى يُزوهش و اثرات مستقيم آنها مد نظر قرار كرفت و يس از بررسى يافته هاى يزٔوهش به بررسى فرضيه اصلى برداخته
همانطور كه ملاحظه مىشود، شاخصهاى مطلق' (مجذور كاى'، ريشه

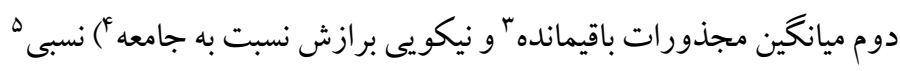

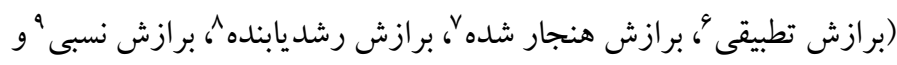

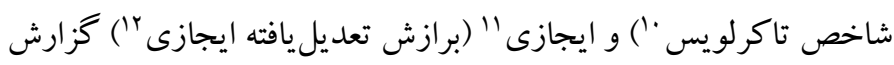
شده است. اين شاخص ها قبل از اصلاح مدل، نشان مىدهد كه مدل در ابتدا
7. Normed Fit Index

8. Incremental Fit Index

9 . Relative Fit Index

10. Tucker-Lewis Index

${ }^{11}$. parsimonious

12. Adjusted Goodness-of-Fit Index
1 . absolute

2. Chi-square

3. Root Mean Squared Error of Approximation

${ }^{4}$. Close Fit of the population

5 . relative

${ }^{6}$. Comparative Fit Index 
هدف بززوهش: واسطه گرى راهبردهاى ياد گيرى در رابطهى بين باورهاى

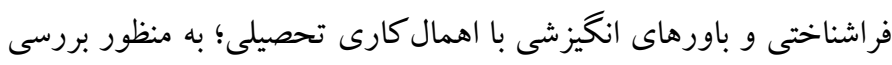

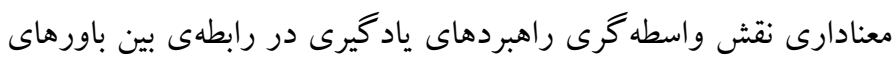

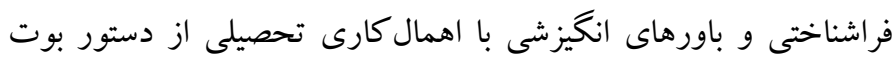

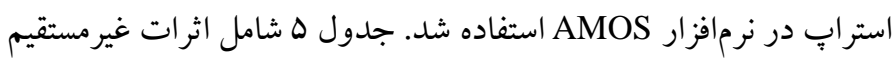

$$
\text { و اثرات كلى متغيرهاى يزٔوهش است. }
$$

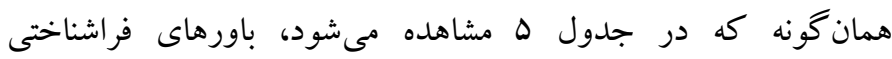

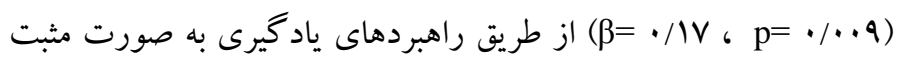

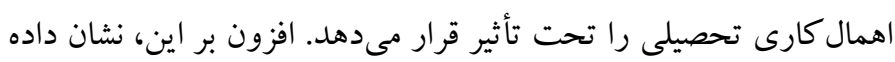

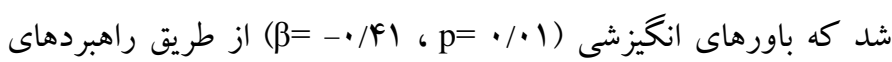
ياد گيرى به صورت منفى، اهمال كارى تحصيلى را تحت تأثير قرار مى دهد.

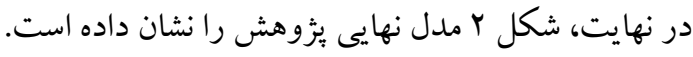

باورهاى فراشناختى و باورهاى انخيزشى بر اهمال كارى تحصيلى؛ برطبق

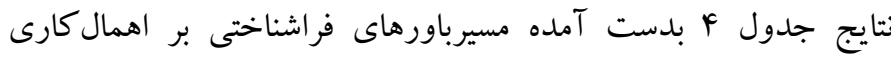

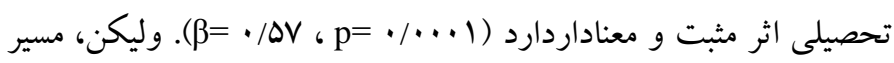

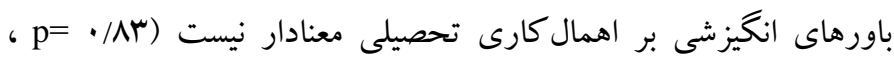
.$(\beta=-\cdot / \cdot r$ باورهاى فراشناختى و باورهاى انخيزشى بر راهبردهاى ياد گيرى؛ در بررسى

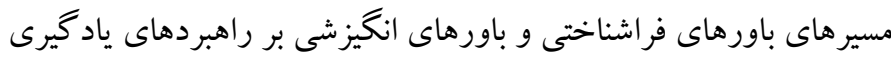

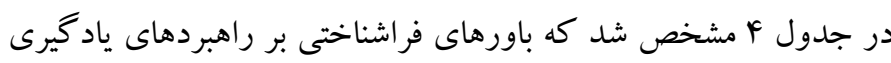

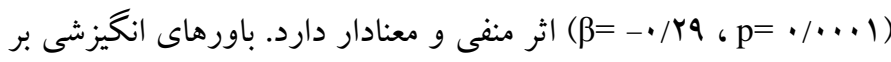

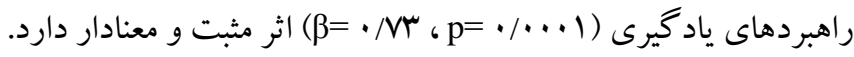

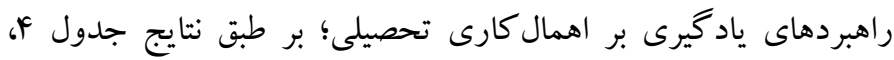

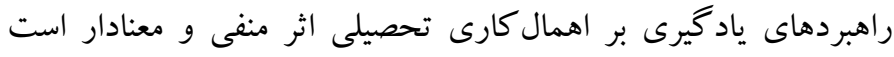

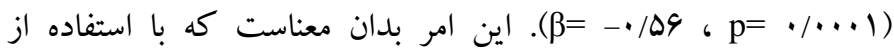
راهبردهاى ياد گيرى موجب كاهش اهمال كارى تحصيلى مى شود.

\begin{tabular}{|c|c|c|c|}
\hline 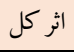 & $\mathrm{P}$ & اثر غيرمستقيم & 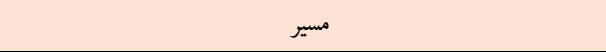 \\
\hline$\cdot / N$ & $\cdot / \cdot 9$ & $\cdot / \mathrm{IV}$ & باورهاى فراشناختى - راهبردهاى يادگيرى - اهمال كارى تحصيلى \\
\hline$-\cdot / A r$ & $\cdot / \cdot 1$ & $-\cdot|+|$ & باورهاى انخيزشى - راهبردهاى يادگيرى - اهمال كارى تحصيلى \\
\hline
\end{tabular}

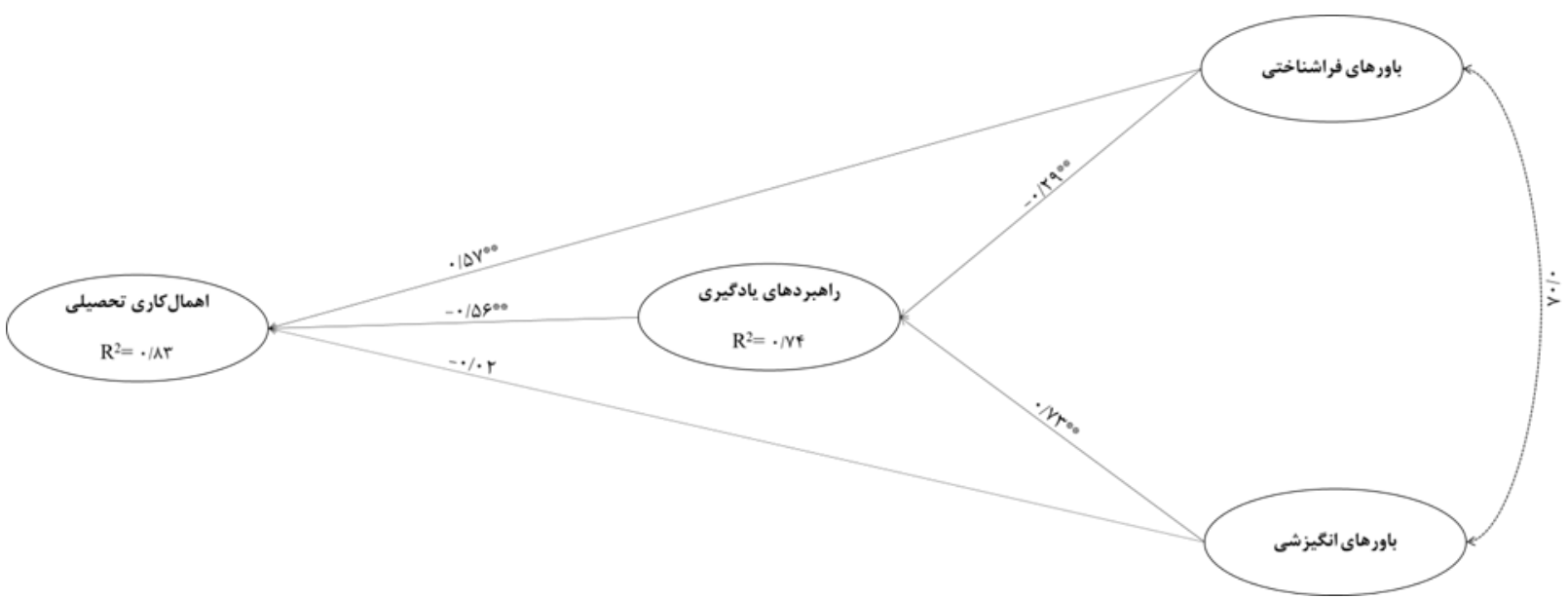

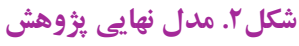

ملاحظه مىشود كه ضريب تعيين راهبردهاى ياد گيرى (RF)

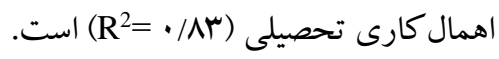

در شكل r مدل نهايى بثزوهش گزارش شده است و مسيرهاى معنادار و

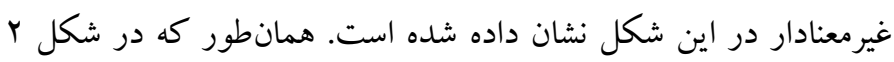


اهمال كارى تحصيلى شخص با اضطراب و تنشهاى زيادى مواجه

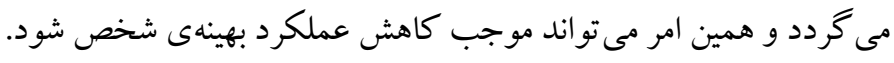

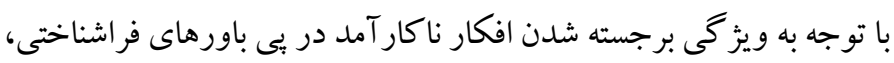

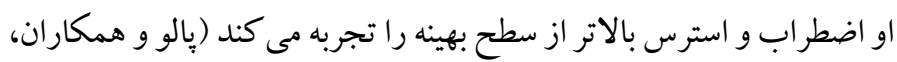
كه اين امر موجب اهمال كارى تحصيلى مى گردد. در زمينهى (Y.IV

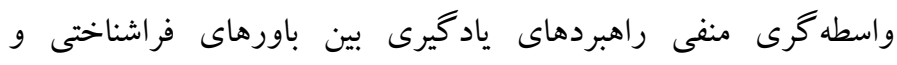
اهمال كارى تحصيلى مى توان بر طبق نظريه شناختى - رفتارى اين مورد

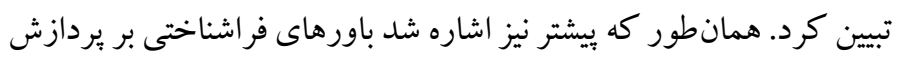

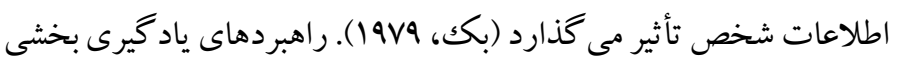
از بردازش اطلاعات شخص است. داشتن باورهاى ناكار آمد زمينه را براى بردازش اطلاعات معيوب فراهم مى كند. شخص نمى تواند هدف خود را در بيى اين باورها شناسايى كند، توجه و تمركز ناكافى دارد، فر آيندهاى خودتنظيمى، بردازش اطلاعات و خود آزمايى او ناقص خو اهد بود و همين امر موجب اهمال كارى تحصيلى مىشود. به عبارت ديخر، زمانى كه ئه شخص باورهاى مثبت و منفى نسبت به اهمال كارى در ذهن خود دارد به جنبههاى مختلف تكليفها نمى تواند توجه كافى داشته باشد و آنها را يردازش كند جون يا در باورهاى مثبت به كارها و اولويتهاى ديخر

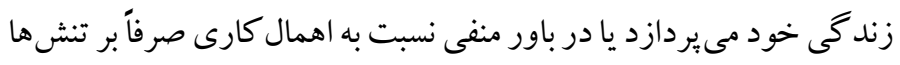
و كاهش تنشها توجه دارد. همجنين، اين موارد زمينه را براى عملكرد ناساز گار در خودتنظيمى، خود آزمايى و هدفمندى فراهم مى كند. تمامى لهى اين موارد در نهايت اهمال كارى تحصيلى به عنوان يكك بيامد رفتارى در يى خواهد داشت. در جهت تبيين نقش واسطه گرى راهبردهاى يادگيرى

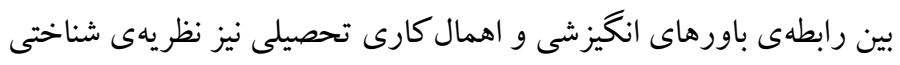

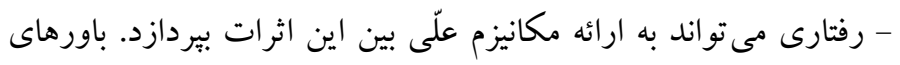

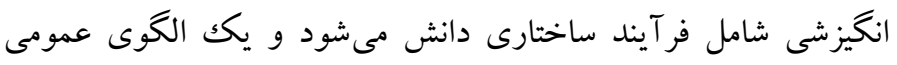
شناختى - اجتماعى از انغيزش را مطرح مى كند و سه سازه انتظار، ارزش

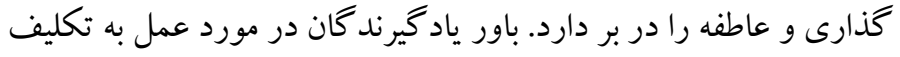
به عنوان انتظار، باور افراد نسبت به علاقه و اهميت يكك تكليف بعد ارزشى دئ داردي و واكنشهاى هيجانى نسبت به تكليف به عنوان بعد عاطفى شناخته

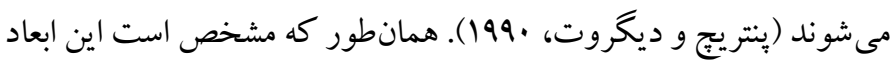

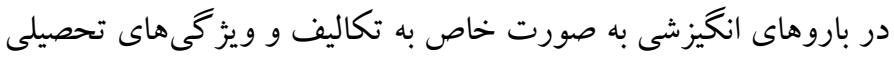

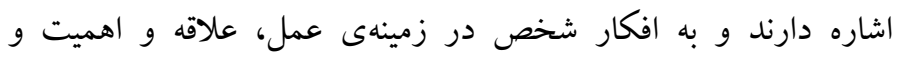

بحث و نتيجه تيرى

براساس يافته هاى يُزوهشى نشان داده شد كه باورهاى فراشناختى نسبت به اهمال كارى به صورت مستقيم بر اهمال كارى تحصيلى اثر مثبت و معنادار

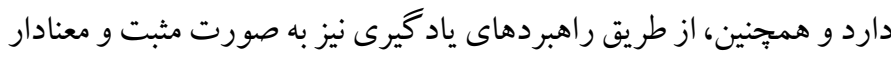
اهمال كارى تحصيلى را تحت تأثير قرار مىدهد. در كنار اين يافتهها

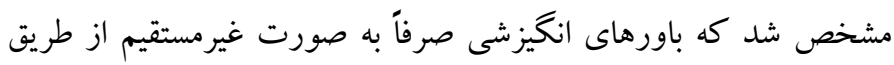
راهبردهاى ياد گيرى بر اهمال كارى تحصيلى اثر منفى و معنادار دارد. در تفسير يافتهى مربوط به باورهاى فراشناختى و اهمال كارى تحصيلى بهري

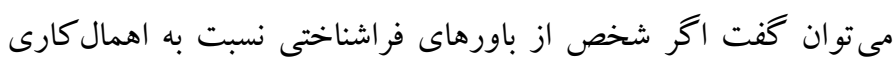
برخوردار باشد زمينه براى اهمال كارى تحصيلى ايجاد مىشود. اين يافته با

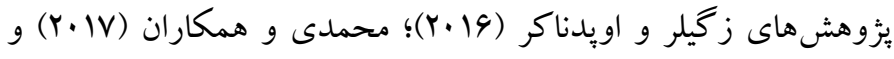

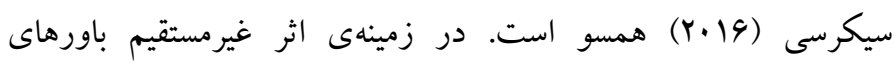

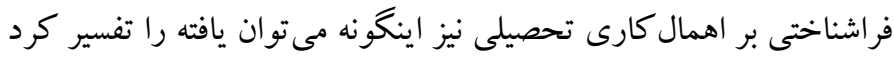

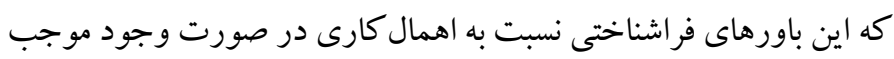

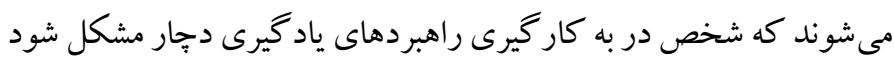
و همين امر زمينه را براى اهمال كارى تحصيلى فراهم كند. اين يافته با دهائ

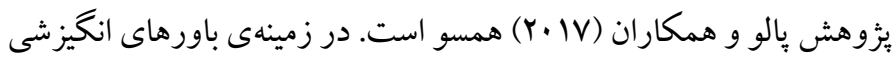
نيز مشخص شد كه باورهاى انخيزشى با فراهم كردن زمينهى استفاده از هدران

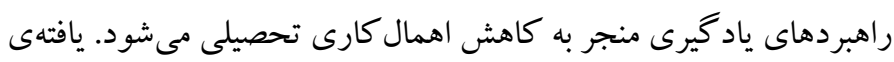

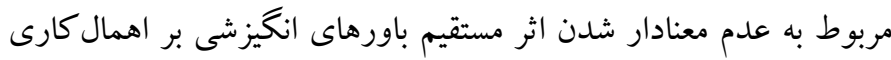

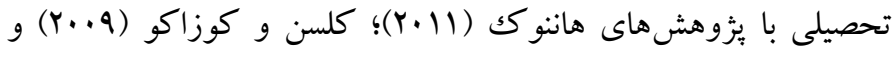

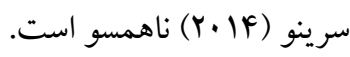
باورهاى فراشناختى به عنوان اطلاعاتى كه شخص در مورد شناخت خود و

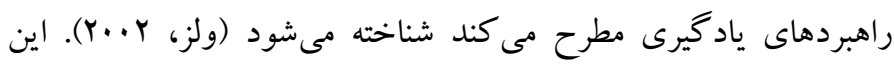

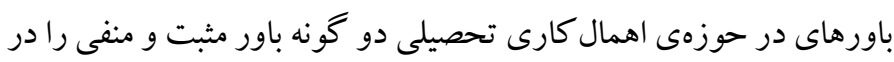

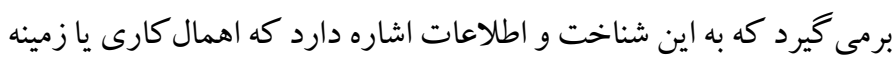

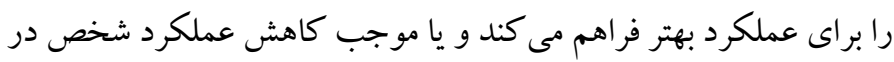

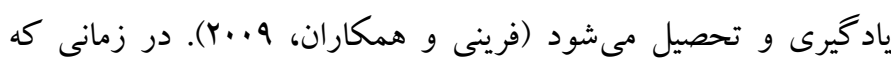

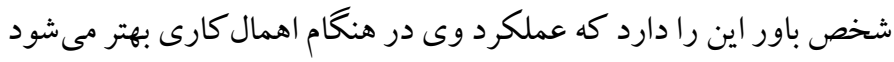
دليلى براى ادامه كار و ييشبرد اهداف خود نمى بيند بلكه اين روند را را مثبت شناسايى مى كند. همين امر موجب آن مى دود كه اقدامى براى كاهش

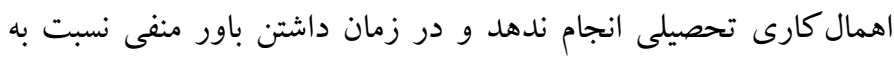


اين إزوهش با محدوديتهايى نيز مواجه بود كه يكى از محدوديتها

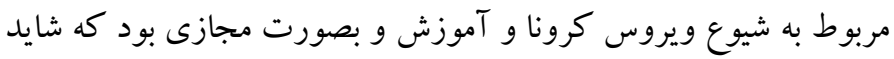
نظر شناختى افراد ادراككشان نسبت به متغيرهاى يُزوهشى تغيير كند.

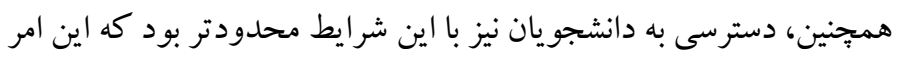

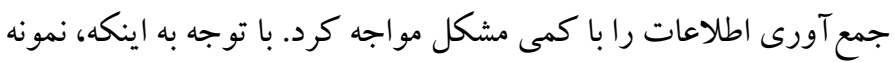
يزّوهش حاضر از دانشجويان دانشخاههاى كرمان است، بايد در تعميم آن آن

به جوامع ديخر احتياط كرد.

ملاحضات اخلاقى ييروى از اصـول اخلاق يثووهش: اين مقاله مسـتخرج از رسـاله دكترى مىباشـــ.

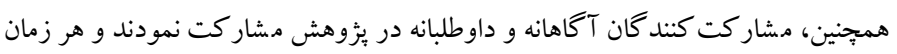

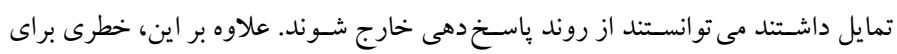
مشار كت كنند كان متصور نشد. حامى مالى: در اين يزوهش هيتج سـازمانى حمايت مالى انجام نداده اسـت و با هزينه بثزوهشخران انجام شده است. نقش هر يكك از نويسند كان: •هدر صد اين بثرهش تو سط يورمو سى و •هدر صد توسط اساتيد راهنما و مشاور انجام شده است. تضاد منافع: هيج گونه تضاد و تعارض منافعى در اين يزوهش وجود نداشت.

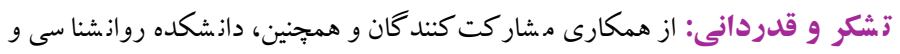
علوم تربيتى و بخش روانشناسى تربيتى دانشگاه سمنان سِاس گز اريم.
واكنشهاى هيجانى نسبت به تكاليف مى يردازند. اين موارد زمينه را براى تعيين اهداف در زمينهى تحصيل، خودتنظمى كه شامل بررسى تو انمندىها و در جهت اهداف حركت كردن و ثبت و ضبط اعمال مىشود، توجه متمر كز بر روى ويز گى هاى تكاليف، يردازش اطلاعات عميق و در نهايت

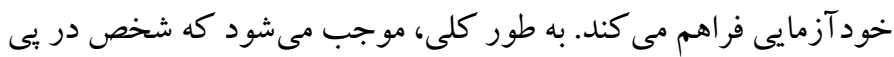

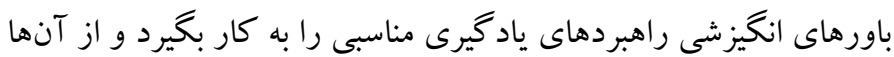
به خوبى بهره بخيرد و در نهايت، اهمال كارى تحصيلى كمترى را تجرئ بهريه

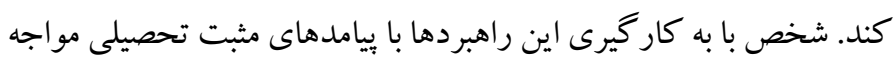
مىشود و عملكرد كار آمدترى را تجربه مى كند.

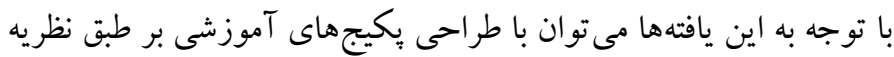

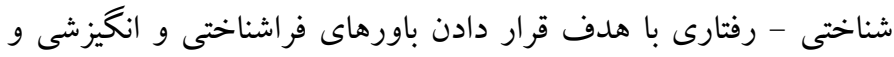

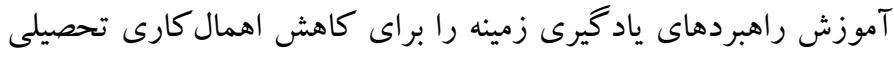

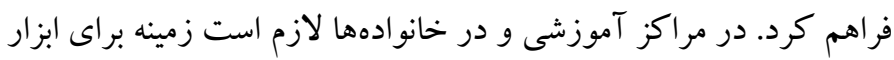
عقايد و باورها نسبت به تكاليف و تحصيل لازم است فراهم شود تا بتوان

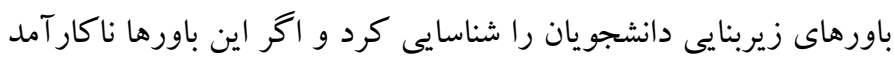
است در جهت اصلاح آنها با توجه به سن رشدى و رشد شناختى افراد

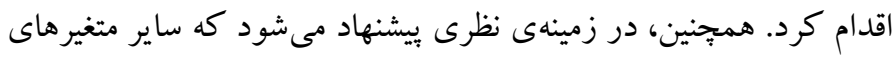

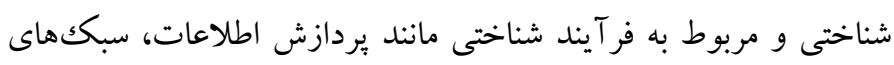

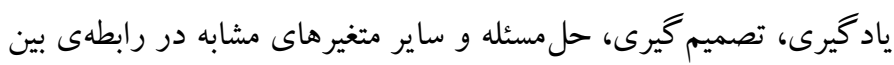

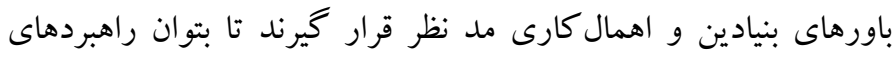
مؤثرى براى كاهش اهمال كارى تحصيلى در نظر گرفت. 


\section{References}

Bahri, A., \& Corebima, A. D. (2015). The contribution of learning motivation and metacognitive skill on cognitive learning outcome of students within different learning strategies. Journal of Baltic Science Education, 14(4), 487. [link]

Balkis, M., \&Duru, E. (2007). The Evaluation of the Major Characteristics and Aspects of the Procrastination in the Framework of Psychological Counseling and Guidance. Educational Sciences: Theory \& Practice, 7(1). [link]

Beck, A. T. (Ed.). (1979). Cognitive therapy of depression. Guilford press. [link]

Cerino, E. S. (2014). Relationships Between Academic Motivation, Self-Efficacy, and Academic Procrastination. Psi Chi Journal of Psychological Research, 19(4), 156-163. [link]

Çikrikci, Ö. (2016). Academic procrastination: The role of metacognitive awareness and educational stress. Mediterranean Journal of Educational Research, 19(1), 39-52. [link]

De Palo, V., Monacis, L., Miceli, S., Sinatra, M., \& Di Nuovo, S. (2017). Decisional procrastination in academic settings: The role of metacognitions and learning strategies. Frontiers in psychology, 8, 973. [link]

Fernie, B. A., Spada, M. M., Nikčević, A. V., Georgiou, G. A., \& Moneta, G. B. (2009). Metacognitive beliefs about procrastination: Development and concurrent validity of a self-report questionnaire. Journal of Cognitive Psychotherapy, 23(4), 283293. [link]

Fuertes, M. C. M., Jose, B. M. D., Nem Singh, M. A. A., Rubio, P. E. P., \& De Guzman, A. B. (2020). The moderating effects of information overload and academic procrastination on the information avoidance behavior among Filipino undergraduate thesis writers. Journal of Librarianship and Information Science, 52(3), 694-712. [link]

Golestani Bakht, T., \& Shokri, M. (2013). The relationship between academic procrastination and metacognitive beliefs. Two Quarterly Journal of Social Cognition, 2 (3), 89_100. (Persian) [link]

Graham, S. (2006). A study of students' metacognitive beliefs about foreign language study and their impact on learning. Foreign language annals, 39(2), 296-309. [link]

Haghbin, M. Mccaffery, A. pychyl, A.T. (2012). The complexity of the relation between fear of failure and pricrastinatin. J Rat-Emo cognitive- Behave ther, 30: 249-263. [link]

Hannok, W. (2011). Procrastination and motivation beliefs of adolescents: A cross-cultural study. Doctor of Philosophy thesis. 1-211. [link]

Hasanzadeh, R., \& Shahmohamadi, F. (2011). Study of emotional intelligence and learning strategies. Procedia-Social and Behavioral Sciences, 29, 1824-1829. (Persian) [link]

İskender, M. (2011). The influence of self-compassion on academic procrastination and dysfunctional attitudes. Educational Research and Reviews, 6(2), 230-234. [link]

Klassen, R. M., \& Kuzucu, E. (2009). Academic procrastination and motivation of adolescents in Turkey. Educational psychology, 29(1), 69-81. [link]

Kline, R. B. (2015). Principles and practice of structural equation modeling. Guilford publications. [Link]

Lee, E. (2005). The relationship of motivation and flow experience to academic procrastination in university students. The Journal of Genetic Psychology, 166(1), 5-15. [link]

Maddahi M. (2017) The role of metacognitive beliefs in the prediction of substance abuse relapse. Journal of psychologicalscience, 16(63), 429-448. (Persian) [Link]

Mahmoudzadeh, Roghayeh, Mohammadkhani Shahram, (2016). Perfectionism and academic procrastination: The mediating role of rumination. Clinical Psychology and Personality, 14, 134-125. (Persian) [link]

McCloskey, J. (2012). Finally, my thesis on academic procrastination.1-84.[link]

MohammadiBytamar, J., Zenoozian, S., Dadashi, M., Saed, O., Hemmat, A., \&Mohammadi, G. (2017). Prevalence of academic procrastination and its association with metacognitive beliefs in Zanjan University of Medical Sciences, Iran. Journal of Mhedical Education Development, 10(27), 84-97. [link]

Moltafet, G., \& Ranjbar, Z. (2015). Prediction of academic procrastination based on personality traits with mediator role of self regulation skills. Journal of psychologicalscience, 14(53), 55-74. (Persian) [Link]

Papageorgiou, C., \& Wells, A. (2003). An empirical test of a clinical metacognitive model of rumination and depression. Cognitive therapy and research, 27(3), 261-273. [link] 
Pintrich, P. R. (2002). The role of metacognitive knowledge in learning, teaching, and assessing. Theory into practice, 41(4), 219-225. [link]

Pintrich, P. R., \& De Groot, E. V. (1990). Motivational and self-regulated learning components of classroom academic performance. Journal of educational psychology, 82(1), 33. [link]

Rafiei, F., Rasooli, S., Najafi Ghezeljeh, T., \& Haqqani, H. (2014). The relationship between academic procrastination and academic success and selfefficacy in nursing students of Tehran University of Medical Sciences in 2012. Iranian Journal of Medical Education, 14 (1), 32_40. (Persian) [link]

Razeqi, F., Mirza Hosseini, H., \& Zargham Hajebi, M. (2020). Modeling the relationship between achievement goals and motivational beliefs with academic procrastination: The mediating role of self-regulatory learning strategies. Journal of Jundishapur Education Development, Quarterly Journal of the Center for the Study and Development of Medical Education, 11 (3), 334_359. (Persian) [link]

Roelofs, J., Onckels, L., \& Muris, P. (2013). Attachment quality and psychopathological symptoms in clinically referred adolescents: the mediating role of early maladaptive schema. Journal of child and family studies, 22(3), 355-387. [link]

Salmanpour, H., Farid, A., Salmanpour, S., \& Qasemzadeh, A. (2014). The relationship between early maladaptive schemas and perfectionism: a test of a causal pattern. New Psychological Research, 55, 98-81. (Persian) [link]

Shahrokhi, M, \& Nasri, S. (2014). Investigating the relationship between perfectionism and exam anxiety with academic procrastination in students. New Educational Thoughts, 38, 183-161. (presian) [link]

Solomon, L. J., \&Rothblum, E. D. (1984). Academic procrastination: Frequency and cognitivebehavioral correlates. Journal of counseling psychology, 31(4), 503. [link]

Steel, P. (2007). The nature of procrastination: a metaanalytic and theoretical review of quintessential self-regulatory failure. Psychological bulletin, 133(1), 65. [link]

Wang, J., Spencer, K., \& Xing, M. (2009). Metacognitive beliefs and strategies in learning Chinese as a foreign language. System, 37(1), 46-56. [link]

Weinstein, C. E., \& Palmer, D. R. (2002). LASSI. User's Manual for those administering Learning and Study Strategies Inventory. [link]
Weinstein, Y., McDermott, K. B., \& Roediger III, H. L. (2010). A comparison of study strategies for passages: Rereading, answering questions, and generating questions. Journal of Experimental Psychology: Applied, 16(3), 308. [link]

Wells, A. (2002). Emotional disorders and metacognition: Innovative cognitive therapy. John Wiley \& Sons. [link]

Wells, A., \& Matthews, G. (1996). Modelling cognition in emotional disorder: The S-REF model. Behaviour research and therapy, 34(11-12), 881-888. [link]

Wolters, C. A. (2003). Understanding procrastination from a self-regulated learning perspective. Journal of educational psychology, 95(1), 179. [link]

Wolters, C. A., \& Rosenthal, H. (2000). The relation between students' motivational beliefs and their use of motivational regulation strategies. International journal of educational research, 33(7-8), 801-820. [link]

Yockey, R. D. (2016). Validation of the short form of the academic procrastination scale. Psychological reports, 118(1), 171-179. [link]

Zahedi, S., \& Fakhri, Z. (2015). Analysis of the factor structure of the list of "learning and study strategies" in students. and Learning Research Education, 12 (1), 67-82. (Persian) [link]

Ziegler, N., \& Opdenakker, M. C. (2018). The development of academic procrastination in firstyear secondary education students: The link with metacognitive self-regulation, self-efficacy, and effort regulation. Learning and Individual Differences, 64, 71-82. [link]

Zolfaghari, H., Zare, H., Farajollahi, M., \& Maleki, H. (2014). The effect of problem solving training on self regulated learning strategies (planning, manitoring \& control, reflection) in students. Journal of psychologicalscience, 13(51), 417-435. (Persian). [Link] 